\title{
Envolvimento paterno aos 12 meses de vida do bebê
}

\author{
Rodrigo Gabbi Polli \\ Marília Reginato Gabriel \\ Cesar Augusto Piccinini \\ Rita de Cassia Sobreira Lopes \\ Universidade Federal do Rio Grande do Sul, RS, Brasil
}

\begin{abstract}
Resumo
O objetivo deste estudo foi investigar o envolvimento paterno de 35 pais (18 a 40 anos), cujo filho tinha 12 meses de vida. Os pais responderam a uma entrevista e as suas respostas foram examinadas através de análise de conteúdo qualitativa, com base em três dimensões do envolvimento paterno: interação, disponibilidade e responsabilidade. Os pais relataram se envolver com o filho de acordo com as necessidades e habilidades específicas dos 12 meses, idade em que o bebê passa a ser mais responsivo. Contudo, alguns pais relataram não ter a habilidade necessária para cuidar de um bebê, o que pode contribuir para um menor envolvimento com o filho. Os resultados do estudo evidenciam que os pais mostraram-se competentes para lidar com um bebê com novas habilidades, mesmo que, em alguns momentos, eles parecessem sentir dificuldades ou ainda preferissem que a mãe realizasse determinadas atividades.
\end{abstract}

Palavras-chave: Envolvimento paterno; Relações pai-criança; Paternidade.

\section{Fathers' involvement during the baby's 12 months}

\begin{abstract}
This study aimed to investigate the paternal involvement of 35 parents (18 to 40 years old), whose child was 12 months old. The fathers answered an interview and their answers were examined through qualitative content analysis, based on three dimensions of paternal involvement: interaction, availability and responsibility. Fathers reported getting involved with the child according to the specific needs and skills of 12 months old when the baby becomes more responsive. However, some parents reported not having the necessary skill to take care of a baby, which can contribute to a reduced involvement with the child. The study results evidence that fathers have showed the competency to deal with a baby with new skills, even if, at times, they seemed to have difficulty or even preferred that the mother perform certain activities.
\end{abstract}

Keywords: Father involvement; Father child relations; Paternity.

\section{Envolvimiento paterno a los 12 meses de vida del bebé}

\section{Resumen}

Este estudio tuvo como objetivo investigar lo envolvimiento paterno de 35 padres ( 18 a 40 años), cuyo hijo tenía 12 meses de edad. Los padres respondieron a una entrevista y sus respuestas se examinaron mediante análisis de contenido cualitativo, basado en tres dimensiones de lo envolvimento paterno: interacción, disponibilidad y responsabilidad. Los padres informaron de involucrarse con el niño de acuerdo a las necesidades y capacidades específicas de los 12 meses de edad, cuando el bebé se vuelve más responsivo. Sin embargo, algunos padres reportaron no tener la habilidad necesaria para cuidar de un bebé, lo que puede contribuir a una participación reducida con el niño. Los resultados del estudio muestran que los padres han demostrado ser competentes para ocuparse de un bebé con nuevas habilidades, aunque, a veces, parece que tienen dificultad o incluso prefiere que la madre realizar ciertas actividades.

Palabras clave: Envolvimiento paterno; Relaciones padre-niño; Paternidad. 
Nos últimos anos, vários estudos têm investigado a paternidade no contexto da relação pai-bebê (Castoldi, Gonçalves, \& Lopes, 2014; Fuertes, Faria, Breeghly, \& Santos, 2015; Sary \& Turnip, 2015). Resultados revelam que no primeiro ano de vida do bebê o pai ${ }^{1}$ já pode ser considerado pelo filho como base segura tanto quanto a mãe (Frascarolo, 2004) e que o envolvimento do pai com o bebê é muito importante para o estabelecimento de um apego seguro (Brown, Mangelsdorf, \& Neff, 2012; Fuertes et al., 2015). Além disso, a participação paterna na vida do filho, sobretudo através de brincadeiras mais ativas, pode influenciar o desenvolvimento social e motor da criança (Manfroi, Macarini, \& Vieira, 2011). Contudo, embora as investigações acerca do envolvimento do pai com seu filho apareçam com mais frequência nos últimos anos, ainda é um tema menos explorado quando comparado a pesquisas envolvendo a maternidade (Vieira et. al, 2014). Isso ocorre, apesar das evidencias indicarem que o envolvimento paterno nos primeiros anos de vida do bebê é muito importante tanto para o seu desenvolvimento quanto para o estabelecimento de uma relação afetiva e segura com o pai.

Aos 12 meses de idade, o bebê está descobrindo as possibilidades do mundo, aprendendo a caminhar, provando as papinhas e convivendo com várias pessoas (Carvalho, Pedrosa, \& Rossetti-Ferreira, 2012). Segundo Winnicott (1958/2005), o final do primeiro ano de vida é marcado pela aquisição da independência. Se a mãe ou substituto materno consegue fornecer ao bebê condições suficientemente boas desde o seu nascimento, ele passa por um processo gradual que o conduz de um estágio no qual a dependência física e emocional com o ambiente é inicialmente absoluta e depois relativa - para um estágio em que a criança avança rumo à independência.

A partir desse processo de dependência para a independência, vai se abrindo mais espaço para que o pai participe cada vez mais na vida do bebê, assumindo junto ao filho outros papéis além de cuidador da díade mãe-bebê ou de substituto materno (Fulgencio, 2007; Winnicott, 1957/1982). Nessa etapa do desenvolvimento, cabe também ao pai ajudar a mulher a desadaptar-se da identificação inicial com o seu bebê, dando início ao processo de separação entre

\footnotetext{
1 Embora em português o termo "pais" refere-se tanto ao pai quanto à mãe, no presente artigo, o termo será empregado apenas para se referir ao genitor masculino, enquanto o termo "pai(s) e mãe(s)" será utilizado para se referir a ambos.

2 Os dados analisados neste estudo sobre gestação e no estudo de Piccinini et al. (2012), que será mencionado a seguir, fazem parte das primeiras fases de coleta de dados do "Estudo Longitudinal de Porto Alegre: Da Gestação à Escola" - ELPA (Piccinini, Tudge, Lopes, \& Sperb, 1998). Os dados que serão apresentando no presente estudo se referem aos $12^{\mathrm{O}}$ mês de vida da criança e também fazem parte do mesmo projeto.
}

a mãe e o filho; o qual, aos poucos, conduzirá a criança à independência (Fulgencio, 2007).

Para Winnicott (1958/2005), a inserção do pai com seus aspectos paternos vai aparecendo como algo novo no desenvolvimento do bebê por volta dos seus 12 meses de idade, alcançando sua plena extensão quando este inicia a andar. Por meio dos cuidados maternos, os aspectos paternos começam a ser sentidos e diferenciados pelo bebê. Nesse momento, o pai não é mais somente um substituto da mãe, mas vai aparecendo na vida do filho trazendo qualidades de firmeza, rigor, ordem, força, limite e introdução do "não" (Fulgencio, 2007). Ao mesmo tempo, o pai continua atuando enquanto facilitador da relação mãebebê, criando condições de apoio para que a qualidade dessa interação mantenha-se ao longo do primeiro ano da criança (Winnicott, 1987/2006).

$\mathrm{O}$ estudo da paternidade tem sido realizado a partir de diversas conceitualizações e perspectivas. Neste artigo, destaca-se o conceito de envolvimento paterno proposto por Lamb, Pleck, Charnov e Levine (1985), organizado em três dimensões da paternidade: interação, disponibilidade e responsabilidade. Interação refere-se ao contato direto do pai com o filho, através do cuidado e das atividades compartilhadas, enquanto a disponibilidade se refere à acessibilidade física e psicológica que oportuniza a interação, o que permite, mas não requer necessariamente, uma interação direta. Por fim, responsabilidade refere-se ao papel do pai de garantir que a criança seja cuidada e que os recursos estejam disponíveis para ela - incluemse nessa dimensão as ansiedades, preocupações e planejamentos inerentes à parentalidade.

Entre os estudos que se baseiam no conceito de envolvimento paterno de Lamb et al. (1985) ao longo do primeiro ano de vida de bebês em desenvolvimento típico, destaca-se o realizado com pais durante a gestação (Piccinini, Silva, Gonçalves, Lopes, \& Tudge, 2004), aos três meses do bebê (Piccinini, Silva, Gonçalves, Lopes, \& Tudge, 2012) e ao longo do primeiro ano de vida deste (Castoldi et al., 2014; Saleh \& Hilton; 2011). Na gestação, o estudo de Piccinini et al. $(2004)^{2}$, realizado com 35 pais de 21 a 40 anos que foram entrevistados, revelou que eles buscavam se envolver com o filho acompanhando as suas esposas em consultas e ultrassonografias, ao mesmo tempo em que proporcionavam apoio emocional à gestante conversando, tranquilizando e estando disponíveis para ela. Além disso, durante a gravidez, os pais interagiam com o bebê por meio da reação ou do contato com as manifestações do filho na barriga da esposa; conferindo ao bebê, já nesse período, características emocionais e físicas. Os pais ainda se mostraram bastante preocupados, 
principalmente com a gestação, parto, filho, sustento financeiro da família, acréscimo de responsabilidades e inexperiência.

Já aos três meses de vida do bebê (Piccinini et al., 2012), as respostas de 38 pais, de 20 a 40 anos, indicaram que eles se envolviam com o filho através dos cuidados dispendidos, ao estarem disponíveis para ele e para a esposa, e ao compartilharem preocupações e responsabilidades com esta, ainda que em menor grau. Destacam-se, nessa fase, as dificuldades que os pais relataram que se depararam ao realizarem os cuidados básicos, ainda vivenciando sentimentos de inadequação e inexperiência.

Por sua vez, aos 12 meses de vida do bebê, uma pesquisa realizada por Saleh e Hilton (2011) com 2.515 pais americanos de diferentes idades também identificou altos níveis de envolvimento paterno, revelando que $42,7 \%$ dos pais relataram interação com os filhos durante mais de cinco dias por semana, $89,3 \%$ relataram altos níveis de disponibilidade, buscando estar junto da família, e $48 \%$ referiram ser pais responsáveis ao ter emprego, dar apoio financeiro e ter acesso a crédito. Estes estudos sugerem que o aumento da idade da criança e o desenvolvimento de suas novas competências contribuem para um maior envolvimento do pai com o filho. Assim sendo, o presente estudo teve como objetivo investigar o envolvimento paterno aos 12 meses de vida do bebê, com base nas três dimensões do envolvimento paterno propostas por Lamb et al. (1985), a saber: interação, disponibilidade e responsabilidade.

\section{Método}

\section{Participantes}

Participaram deste estudo 35 pais, com idades entre 18 e 40 anos. Quanto ao nível de escolaridade, a maioria dos pais tinha ensino médio completo (31,4\%; $5,7 \%$ incompleto), seguido por superior completo $(17,14 \% ; 14,3 \%$ incompleto), fundamental completo $(8,57 \% ; 17,14 \%$ incompleto) e pós-graduação $(5,7 \%)$. No início do estudo, todos viviam com a mãe da criança na região metropolitana de Porto Alegre. O bebê foco do estudo tinha 12 meses de idade $(51,4 \%$ meninas e $48,6 \%$ meninos) e era o primeiro filho do casal. Os participantes integraram o "Estudo Longitudinal de Porto Alegre: Da Gestação à Escola" - ELPA (Piccinini et al., 1998) 3 e já tinham participado de duas coletas de dados, na gestação e terceiro mês de vida do bebê, antes de participarem da coleta de dados dos 12 meses, foco do presente estudo. Afora os dados sociodemográficos coletados na gestação, o presente estudo considerou apenas dados obtidos no $12^{\mathrm{O}}$ mês de vida do bebê. Para fins deste estudo, foram incluídos todos os pais que aceitaram participar desta fase e responderam aos instrumentos selecionados para este artigo. O ELPA recebeu aprovação do Comitê de Ética da UFRGS (Resolução no 2006596).

\section{Procedimentos e instrumentos}

De acordo com os procedimentos do projeto ELPA (Piccinini et al., 1998), as mães e os pais foram convidados a participar do estudo ainda durante a gravidez da companheira. Neste primeiro momento, a gestante era informada a respeito dos objetivos do estudo e respondia à Ficha de contato inicial, a qual buscava verificar se a família atendia aos critérios de inclusão do estudo. Era, então, marcado um encontro na residência dos participantes, quando a mãe e o pai assinavam o Termo de consentimento livre e esclarecido e respondiam à Entrevista sobre dados demográficos da família, que visava obter informações adicionais sobre os participantes, como idade, escolaridade, estado civil, ocupação, religião e grupo étnico. Após as coletas de dados realizadas na gestação e no 3 o mês, as famílias foram novamente contatadas aos 12 meses de vida do bebê. Nesse momento, o pai respondeu à Entrevista sobre a experiência da paternidade, cujas respostas foram analisadas para fins do presente estudo. Esta entrevista estruturada investigava diversos aspectos da paternidade como, por exemplo, as impressões do pai em relação ao filho, seu desenvolvimento e temperamento, seus sentimentos e dificuldades enquanto pai, o dia a dia do pai com o bebê, as tarefas assumidas nos cuidados com o filho, os tipos de brincadeiras que fazia e as suas percepções sobre a companheira como mãe. A entrevista era estruturada, realizada de forma semidirigida, e durava aproximadamente uma hora, era gravada e foi posteriormente transcrita.

\section{Resultados}

As respostas dos pais à entrevista foram examinadas através de análise de conteúdo qualitativa (Laville \& Dionne, 1999) com o intuito de investigar o seu envolvimento com o bebê. Para tanto, foi utilizada uma estrutura de categorias baseadas nas três dimensões

\footnotetext{
${ }_{3}$ Este estudo teve por objetivo investigar os aspectos subjetivos e comportamentais das interações pai-mãe-bebê, assim como as atividades diárias da criança em seus contextos habituais, o comportamento social de crianças pré-escolares e sua transição para a escola de ensino fundamental. Iniciou acompanhando 81 gestantes primíparas que não apresentavam intercorrências clínicas com elas mesmas ou com o bebê. Os maridos ou companheiros também foram convidados a participar do estudo caso residissem juntos em situação matrimonial. Foram realizadas várias coletas de dados desde a gestação até os oito anos das crianças (gestação, $3^{\circ}$, $, 8^{\circ}, 12^{\circ}$, $18^{\circ}, 24^{\circ}, 30^{\circ}, 36^{\circ}$ mês e $6^{\circ}, 7^{\circ}$ e $8^{\circ}$ ano), durante as quais se aplicou diversas entrevistas, instrumentos psicológicos e se realizou observação das interações pai-mãe-bebê.
} 
propostas por Lamb et al. (1985), a saber: interação, disponibilidade e responsabilidade. Em cada categoria de análise, utilizou-se subcategorias baseadas na literatura (Piccinini et al., 2004, 2012) e nos próprios dados. Durante o procedimento de análise, dois dos autores do presente estudo leram exaustivamente todas as entrevistas e classificaram os relatos dos pais nas categorias de análise. Em caso de discordância, um terceiro autor foi consultado. Apresenta-se, a seguir, cada categoria e subcategorias, ilustrando-as com relatos paternos.

\section{Interação com o bebê}

Nesta categoria, foram incluídos os relatos dos pais a respeito das atividades de cuidado e lazer, que eles realizavam com o bebê, compreendendo oito subcategorias: brincar, cuidar, passear, colocar limites, conversar, estimular, demonstrar afeto e distrair. Quanto ao brincar, a grande maioria dos pais $(80 \%)^{4}$ relatou brincar com seus filhos, sendo que as brincadeiras com objetos (bola, boneca, urso de pelúcia) e com o próprio corpo (esconder, correr, escalar o corpo do pai) foram citadas por eles: "É brincar de esconder, ele chega atrás, espia, ai eu espio ele, ele adora. Adora jogar bola" (P27).

Da mesma forma, a grande maioria dos pais $(80 \%)$ referiu situações de cuidado do bebê. Entre outros relatos, eles referiram realizar cuidados básicos, como trocar fraldas, roupas, alimentar: "Faço tudo, dar comidinha, tudo que tem que fazer eu faço com ela" (P32). Os pais também mencionaram cuidar do bebê por meio de ações como estar atento, cuidar para o bebê não se machucar: "Quando ela era menor era mais fácil, ela ficava quietinha, só que agora não, se tu ratear ela se vira, aí ela tá cocô, já vira aquela lambança. Então tem que ter uma série de cuidados maior" (P30); acalmar: "Hoje, por exemplo, ela tava com sono, eu acho, eu peguei ela no colo, demorou um tempinho, mas ela se acalmou" (P12); e levar ao médico e dar medicação: "A gente vai no pediatra, eu sempre vou junto, sempre dou um jeito de ir junto" (P31). Dentre os cuidados disponibilizados para os filhos, muitos pais (31\%) referiam trocar a fralda como a tarefa que eles menos gostavam de fazer com o bebê, justificando a sua fala pela falta de jeito que eles teriam para fazer isso.

Passear com o bebê também era uma interação que a maioria dos pais $(57 \%)$ relatou fazer com o bebê.

\footnotetext{
${ }_{4}$ Para facilitar a exposição dos achados foi utilizada a seguinte descrição, quanto ao número de participantes que fizeram relatos classificados em cada categoria: um/alguns pais: 1 a $9(25 \%)$; muitos pais: $10(28 \%)$ a $18(51 \%)$; a maioria dos pais: $19(54 \%)$ a $27(77 \%)$; a grande maioria/todos os pais: 28 $(80 \%)$ a $35(100 \%)$. Já a autoria das vinhetas é identificada pela letra "P" seguida do número do caso.
}

Os passeios geralmente são aqueles em que o bebê acompanha o pai em alguma atividade, como ir ao mercado, shopping, casa dos avós, bem como aqueles que têm o intuito de levar o bebê para ver outras pessoas e se divertir em parques e praças: "Hoje eu acordei de manhã e ele estava inquieto. Dai eu fui lá, troquei a roupa dele e saí com ele a caminhar. Pego a mãozinha dele e saio" (P10). Muitos pais descreveram as interações de brincadeira (48\%) e passeio (31\%) com o bebê como as atividades que eles mais gostavam de fazer com o filho, principalmente nessa idade em que o bebê já está mais responsivo (ex.: dá a mão quando o pai pede, responde com gestos ou algumas palavras quando o pai fala com ele).

Interações com o bebê que visavam limitar algum comportamento do filho foram citadas por muitos pais (45\%). Dizer "não" para os comportamentos indesejados do bebê foi uma das interações mencionadas pelos pais: "Ele tem já umas estratégias, se jogar no chão. É uma coisa que eu acho um saco, eu me estresso com ele, eu brigo com ele, digo: 'olha meu, te orienta", (P13). Bater no bebê também foi uma interação citada pelos pais como modo de diminuir comportamentos indesejados do filho: "Até umas palmadas ele andou tendo que levar, porque se atirou pra trás e é uma coisa que eu tenho pavor" (P14).

Conversar com o bebê foi relatado por muitos pais (28\%), inclusive como uma maneira de ensinar o filho o que se espera dele: "Eu converso, mostro as coisas pra ele, digo o que é certo, o que é errado. 'Cuida a plantinha porque é a natureza, tem que cuidar'. Então eu gosto bastante de conversar e explicar as coisas pra ele" (P27). Além disso, a conversa, com uma reciprocidade entre pai e bebê, era abordada por eles como algo novo na interação: "Agora ela tá começando a falar. Eu chego em casa e ela: 'Bá, ah'. Ela conversa enrolado, fala, fala, fala enrolado. Eu não sei o que ela quer dizer" (P5).

Alguns pais (17\%) referiram situações em que estimulavam o desenvolvimento do bebê, como a falar: "A gente que fica puxando por ela, tanto 'papai' quanto 'mamãe', a gente incentiva pra ver se ela fala mesmo" (P2); caminhar: "A gente começa a incentivar, começa a chamar ela: 'Vem aqui com o papai, vem aqui com a mamãe'. Pra ver ela desenvolver logo isso" (P21); e a cognição do bebê: "A gente ensina uma coisa e se perguntar dali dois dias ele sabe. Tipo eu ensinei 'os anjinhos lá no céu'. E agora eu pergunto pra ele: 'E os anjinhos, filho?' E ele olha pro céu” (P14).

Alguns pais (22\%) disseram demonstrar afeto para o bebê em interações como abraçar, beijar ou retribuir manifestações de afeto do filho: "É uma realização quando a gente chega e ele vem pro lado te abraçar, 
ele já vem caminhando pro teu lado, se gruda" (P27). Também foram mencionadas por dois pais demonstrações de afeto após terem colocado limites ou batido no bebê: "Depois que ele vê que você foi duro mesmo com ele, a gente fica com aquelas manifestações de carinho" (P15).

Apenas três pais mencionaram que distraiam o bebê. As situações citadas pelos pais foram referentes a momentos em que o filho não aceitava fazer a atividade prevista, como comer, trocar fralda ou dormir: "Se ele não quer trocar: 'Olha o dálmata. Ó, o dálmata vai cantar pra ti'. Só em falar ele já para e já olha o dálmata" (P27); bem como distrair era uma maneira dos pais conseguirem não fazer aquilo que o bebê queria no momento: "Ela quer mamar, e eu não posso dar de mamar, e ai tem que botar uma música, dançar com ela, brincar" (P22).

Através desses relatos pode-se perceber que os pais interagiam com os seus filhos de diversos modos, sendo o brincar e o cuidar as principais formas de interação que eles estabeleceram com o bebê aos 12 meses. Com relação ao cuidar, trocar a fralda foi referida como a tarefa que eles menos gostavam de fazer. Além disso, os pais também mencionaram interagir com o filho passeando, colocando limites, conversando - sendo a conversa entre pai e filho algo novo, uma vez que o bebê estava recém começando a falar -, estimulando, demonstrando afeto e/ou distraindo. Brincar e passear foram as atividades que os pais relataram mais gostar de realizar com o filho nessa idade.

\section{Disponibilidade}

Essa categoria se refere aos relatos dos pais sobre sua disponibilidade de tempo e atenção para o bebê e para a família. Ela consiste em duas subcategorias: quantidade de tempo e avaliação do tempo com o bebê. Com relação à quantidade de tempo com o bebê, a maioria dos pais (74\%) referiu que disponibiliza algum momento do dia ou da semana para estar junto ao filho: "Se for meia hora, tem uma meia hora reservada pra ele. Em função disso, tanto eu quanto ele a gente tá matando a saudade do dia todo, tem contato né" (P14). Para muitos pais (45\%), o tempo que eles tinham disponível para estar com o bebê era ao final de tarde e/ ou à noite: "Mais que eu fico com ele é de noite. Então, é que eu chego e bah, primeira coisa é o [filho], bah, fico com ele, dou janta se ele não tiver jantado ainda" (P10); e/ou de manhã, geralmente antes de saírem para trabalhar (31\%): "De manhã cedo quando eu levanto, primeira coisa é ela, pego ela, tal, vou brincar com ela um pouco. Geralmente minha manhã até ir trabalhar assim, gira em torno dela" (P19). Além disso, alguns pais dispunham dos finais de semana $(25 \%)$ e da hora do almoço (20\%) para fazer companhia ao bebê. Apenas um pai (P20), por não estar trabalhando, passava o dia todo com o filho.

Embora a maioria dos pais (74\%) tenha manifestado que disponibilizava algum momento do dia para estar junto ao bebê, muitos (31\%) avaliaram ter "pouco tempo" para ficar com ele, o que acarretava uma menor participação na rotina do filho: "Eu sou meio ausente, saio de manhã cedo e volto tarde. Eu fico muito longe dela. Pra mim, dia a dia é só no domingo, porque eu fico pouco com ela" (P17). Além disso, o tempo que o pai tinha disponível para estar com o bebê foi descrito por muitos participantes $(40 \%)$ como limitado pela rotina de trabalho: "Eu acho que eu poderia ter mais tempo pra ficar com ela, estudo de noite, trabalho. Por ser militar, às vezes, eu fico muito tempo fora, viajo. Acho que é o único problema, assim, tempo com ela" (P29). Do mesmo modo, o cansaço causado pela rotina, principalmente de trabalho e demais questões pessoais, restringia o envolvimento de alguns pais (22\%): "Caminhar ele quer toda hora. Ai tem hora que a gente está meio cansado, que dói. Dai tu pega e não quer ficar com ele, ou larga ele no carrinho, ou no chiqueirinho, dai ele fica brabo" (P10); "Eu achei que eu teria mais paciência, teria mais saco pra 'coitadinho, tá chorando, vou lá dar colinho'. Só que o saco acaba na primeira levantada [...] No segundo mês, tu já não quer mais nem ver na tua frente" (P13). Apesar de cansados, alguns pais (17\%) relataram participar mesmo assim da vida dos bebês, uma vez que ficar com o filho era legal e recompensador: "Se eu chego em casa cansado e o [filho] tá em casa, eu começo a brincar com ele, eu perco todo o cansaço brincando com ele" (P24). Por fim, estudar (11\%) foi mencionado como também limitando o tempo que alguns pais tinham disponível para ficar com o filho.

Em decorrência do afastamento cotidiano do bebê, alguns pais (17\%) expressaram sentir saudades do filho: "Como eu passo o dia todo fora, tô com saudade dele toda hora. Tô na parada de ônibus ou tô pegando o carro pra sair ejá tô com saudades dele. Pô, vou passar o dia todo longe" (P27). Embora tenham avaliado o tempo que dispõem para ficar com o bebê como pouco e do sentimento de saudades, somente um pai (P29) referiu que tentava suprir a sua ausência ligando para falar com a filha: "Desde que ela nasceu, eu viajei algum tempo, mas ela não ficou muito assim, acho que não deu muita saudade, porque eu ligava sempre". Dois pais relataram estar satisfeitos com o tempo que tinham disponível para o filho: "Eu acho que tá bom. Um pouco todo o dia" (P10).

A partir destes resultados, pode-se perceber que os pais referiram disponibilizar algum momento para 
estar junto do filho, geralmente ao final da tarde e/ ou à noite. Apesar disso, os pais avaliaram como pouco o tempo que eles tinham para ficar com o bebê, estando esse limitado principalmente devido à rotina de trabalho, o que ocasionava uma menor participação paterna. Devido a esse afastamento cotidiano, saudade do bebê foi um dos sentimentos vivenciados pelos pais. Contudo, apareceram também relatos de falta de disponibilidade e mesmo falta de paciência em atender as demandas do bebê, indicando variações bastante grandes entre os pais.

\section{Responsabilidade}

Essa categoria refere-se aos relatos dos pais sobre as responsabilidades que assumiam com o bebê no que diz respeito à participação e à influência na rotina, em aspectos de cuidado e educação, e é composta por cinco subcategorias: participação nas decisões, mãe como principal responsável, conversa sobre cuidado/educação, aumento das responsabilidades, e preocupações.

Com relação à participação nas decisões, a maioria dos pais $(60 \%)$ relatou participar nas decisões sobre o bebê, especialmente sobre a escolha do cuidado alternativo: "Ela [mãe] começa a trabalhar e aí vamos ver se ele vai ficar com a minha mãe, com a sogra, vai ficar com um conhecido. Creche tu não sabe como é tratado. É difícil pra quem é pai largar" (P25). Mesmo com a participação nas decisões, a maioria dos pais (57\%) referiu a mãe como principal responsável pelo bebê, principalmente pelos seus cuidados básicos: "Ela tem muito mais atividade que eu. Eu sou auxiliar" (P21). Outro pai referiu não perceber as necessidades do bebê tanto quanto a mãe: "Essa parte de tarefas a maioria é com ela. Se ele tiver cocô, a gente sente o cheiro, ai tudo bem, mas se ele tiver xixi, eu não sei e ela sabe" (P24).

Mesmo a mãe sendo a principal responsável, a maioria dos pais $(54 \%)$ relatou conversas sobre cuidado e educação do bebê com a esposa. Houve pais que referiram conversar sobre o modo de colocar limites no bebê: "Eu e a mãe dele, de noite, [...] a gente conversa. Eu digo pra ela: 'Tu não tem coragem de brigar com o teu filho'. [...] Agora ela já tá mais brigona: 'Tu briga, mas só quando ele errar,", (P24). Outros pais mencionaram conversar sobre situações que o desagradavam: "Eu falo pra [mãe] falar pra mãe dela não fazer que eu não gosto. Ela [bebê] não precisa de doce, não faz falta pra ela, até quando nós acharmos que tem que dar. Isso é uma coisa que sou contra" (P2). Ainda, alguns pais (25\%) relataram que, após um ano do bebê, ainda sentiam o aumento das responsabilidades: "Me sinto com mais responsabilidade, me sinto olhando mais pro futuro. Pensando já na família" (P19).

Dentre as responsabilidades dos pais, estão as suas preocupações com o bebê. Nesse sentido, a maioria dos pais $(77 \%)$ se revelou preocupada com a saúde e com o desenvolvimento saudável do filho. Tais preocupações envolvem tanto cuidados relacionados ao bebê não ficar doente - levando ao pediatra, por exemplo - e ter hábitos saudáveis de alimentação, sono e higiene (40\%): "Com outras pessoas eu não deixo [o filho], não gosto de deixar. De repente não vão dar alimentação direito assim pra ele, correto, uma fruta, de repente dá uma fruta. Que eles não cuidem direito" (P20); como ficar junto do filho para evitar que ele se machuque (31\%): "Agora é bem pior, porque ela não para, principalmente quando ela vem pro pátio, ela pega o cocô dos cachorros, ela entra dentro da água dos cachorros, ela come a ração dos cachorros. Tem que tá sempre em função" (P18).

Ao mesmo tempo, muitos pais (48\%) também relataram estar preocupados com a educação do filho, principalmente no que se refere à aprendizagem e à estimulação do bebê para que este se desenvolva (20\%): "Minha preocupação, às vezes a gente passa desapercebido determinadas coisa que já se poderia, não forçando, mas dando uma oportunidade de a criança já ir desenvolvendo e a gente em casa acaba passando em branco isso, não percebe" (P15); e à socialização do filho (20\%): "Tá começando a ficar numa hora boa dela ter mais relação com outras crianças porque ela acaba ficando muito com nós, comigo, com a [mãe], então é bom ela se socializar um pouco mais daqui pra frente" (P16). Ainda, alguns pais (14\%) se mostraram preocupados com a boa criação do filho no que diz respeito a transmitir para ele valores e bons modos: "Primeiro pra que ela tivesse um conceito de integração e divisão de coisas. [...] põe empregada cuidando em casa, mas aí não ia conviver com outras crianças, não ia aprender a dividir, a respeitar, a cumprir horário" (P35).

Além disso, a maioria dos pais (57\%) referiu estar preocupada em ser um bom pai. Dessa forma, eles relataram que procuravam fazer o que podiam pelo filho, não deixando faltar nada para ele e proporcionando tudo o que o bebê precisava, como carinho, amor, atenção, cuidados e limites: "Procuro dar atenção pra elas e fazer as coisas pra elas quando eu tô perto, procuro não deixar faltar nada e procuro, quando posso tá perto delas, dar atenção" (P17). Contudo, para dois pais, essa preocupação em ser um bom pai apareceu, em certa medida, atrelada à cobrança da esposa de que eles se envolvessem e participassem da vida dos filhos: "Eu sou um pai que eu procuro fazer o que dá, 
sabe, dentro do possivel, é claro, fazer o que eu posso fazer por ela, passear, brincar, porque a [mãe] me cobra" (P1).

Ao mesmo tempo, a maioria dos pais (51\%) se mostrou preocupada quanto aos cuidados fornecidos por outras pessoas (avós, tios, amigos, babá e creche). Tais preocupações estavam relacionadas principalmente ao fato de os pais não saberem como era o cuidado disponibilizado por essas pessoas ou instituições (34\%), sobretudo para os pais que estavam pensando em colocar os seus filhos na creche: "Tu deixa ali, mas na real tu não sabe o que tá se passando, assim como pode tá sendo ótimo pra criança, tu deixa ali confiando, só que na real tu não sabe, tu fica com um pouco de apreensão" (P30). Ao mesmo tempo, os pais referiram que essas formas de cuidados possuíam algumas características consideradas negativas por eles (28\%), o que os deixava preocupados: "Ela não pode ficar com a dinda porque não está bem cuidada, porque a gente acha que ela não vai saber cuidar bem da nossa filha direito como a gente cuidaria” (P22). Apesar disso, muitos pais (45\%) consideraram positivo o cuidado disponibilizado por outras pessoas aos seus filhos. Estes relatos revelam que os pais vivenciavam sentimentos ambivalentes ao terem que deixar o bebê em cuidado alternativo.

Por fim, alguns pais ainda relataram estar preocupados com o futuro do filho (20\%): "Quando o [filho] tiver 21 anos eu quero que ele já teja morando sozinho, entende, esse tipo de coisa, eu gostaria que ele assumisse a vida dele. Fosse independente nesse sentido assim, de conseguir resolver as suas coisas" (P13); com a sobrecarga da esposa com relação aos cuidados do bebê (17\%): "Tem essa senhora que a gente deixa o [filho]. Bom pros dois porque o [filho] tá tendo contato com outras crianças e pra [mãe] porque dá uma folga pra ela descansar. Porque criança realmente estressa, o [filho] agita muito" (P15); e com o sustento financeiro da família (11\%): "Eu disse pra ele que Deus não desampare o pai e a mãe, pra quando tiver o teu maninho, a tua maninha, poder dar o mesmo que a gente te deu e poder dar mais ainda pra ti" (P14).

Juntos, os relatos acima revelam que os pais mencionaram assumir diversas responsabilidades com o bebê aos 12 meses, sobretudo participando nas decisões sobre o filho e/ou conversando com a mãe sobre aspectos relacionados ao seu cuidado e educação. Apesar de os pais terem referido sentir certo aumento das responsabilidades, as mães foram percebidas como as principais responsáveis pelo bebê, especialmente por proverem os cuidados básicos. Os pais ainda se mostraram preocupados com o filho, principalmente com a saúde e a educação do bebê, e em serem bons pais. Preocupações com os cuidados fornecidos por outras pessoas, com o futuro do filho, com a sobrecarga da esposa e com o sustento financeiro da família também foram relatadas pelos pais.

\section{Discussão}

Os resultados do presente estudo revelam que, aos 12 meses de vida do filho, os pais se envolviam com o bebê de acordo com as necessidades do filho, especialmente através de cuidados e brincadeiras, bem como em função das habilidades que os filhos estavam adquirindo. Com relação à interação paibebê, os resultados do presente estudo revelam que os pais relataram interagir com seus bebês também de acordo com esta etapa do desenvolvimento - cuidando de suas necessidades e promovendo o processo de autonomia do bebê. A grande maioria dos pais citou situações de cuidado como um modo de interagir com o filho, participando especialmente de momentos de alimentação, possivelmente pela introdução da alimentação sólida. Em meses anteriores, o uso da amamentação podia contribuir para limitar as interações com o bebê, como destacado pelo estudo de Piccinini et al. (2012), realizado com os mesmos pais do presente estudo, quando os bebês estavam com três meses e, mesmo anteriormente, quando o contato indireto com o bebê predominava durante a gestação (Piccinini et al., 2004). Na verdade, o final do primeiro ano de vida é marcado por uma maior independência do bebê, quando também vai se abrindo mais espaço para que o pai participe cada vez mais na vida do bebê, assumindo junto ao filho outros papéis além de cuidador da díade mãe-bebê ou de substituto materno (Fulgencio, 2007; Winnicott, 1957/1982).

Relatos sobre não ter habilidade para realizar alguns cuidados, como trocar fralda, foram trazidos pelos pais neste estudo, da mesma forma que no estudo de Piccinini et al. (2012), aos três meses do bebê. Embora pudesse haver a expectativa de uma maior segurança no manejo com o bebê após o primeiro ano de vida, essa avaliação sobre o seu próprio desempenho pode estar relacionada, entre outros fatores, ao fato de o pai não ser o principal cuidador da criança, por isso mencionando uma menor intimidade com as atividades de cuidado (Castoldi et al., 2014). De qualquer modo, entende-se que as crenças sobre sua habilidade nos cuidados do filho, entre outros fatores (ex.: satisfação conjugal), estão diretamente relacionadas com o envolvimento paterno - quanto menos se consideram eficientes, menos se envolvem com o bebê (Kwok, Ling, Leung, \& Li, 2013). Por outro lado, um maior 
envolvimento por parte do pai parece estar relacionado à boa qualidade dos relacionamentos conjugal e familiar, sendo que a presença de conflitos no casal pode levar a mãe a solicitar e facilitar menos a participação do pai (Falceto et al., 2008; McHale et al., 2004).

Da mesma forma, brincar com o bebê também foi uma categoria que incluiu a maioria dos pais. As brincadeiras paternas foram descritas como intermediadas por objetos simples relativos ao mundo infantil (boneca e bola), bem como com o próprio corpo, algumas delas tendo o objetivo de estimular o bebê. Passear e demonstrar afeto também foram interações citadas pelos pais como modo de haver trocas com o filho, que nesta fase, se apresenta mais responsivo às interações. A atividade de brincar do pai tende a ser considerada mais ativa e intensa que a materna mesmo no primeiro ano de vida (Premberg, Hellström, \& Berg, 2008), embora, no presente estudo, as brincadeiras pareceram ser menos ativas e intensas, como brincar de boneca e até passear no colo ou de carrinho. Além disso, segundo Lindsey, Cremeens e Caldera (2010), os pais vocalizam mais com o bebê nessas interações, quando comparadas com momentos de cuidado do bebê. Isso pode ser explicado, de acordo com os resultados do presente estudo, pelo fato dos pais gostarem mais de brincar do que realizar atividades de cuidado do filho, além do que, nesse último caso, há uma necessidade maior de concentração dos pais para o desempenho da atividade.

Conversar e colocar limites também foram modos de interagir com o bebê, visando transmitir ensinamentos para ele. Isso também se deve pelo fato do bebê, nesta fase, já começar a expressar-se verbalmente com um pouco mais de clareza do que o balbucio ou troca de expressões faciais aos três meses (Piccinini et al., 2012). Inclusive, alguns pais, frente à demonstração mais intensa das vontades por vezes não apropriadas do bebê e devido a sua inabilidade para se controlar, acabaram utilizando palmadas como práticas de contenção do filho. Esse resultado pode ser visto também entre as mães de bebês entre um e 12 meses (Altafim, Schiavo e Rodrigues, 2008), as quais referiram utilizar mais práticas negativas quanto mais velhos eram os bebês. Esses resultados podem estar refletindo as dificuldades dos pais e das mães em lidarem com um aspecto esperado do desenvolvimento emocional do bebê, muitas vezes interpretando as expressões do bebê como um afronte a eles ou uma desobediência, e não como expressão de uma busca de autonomia do bebê. Apesar de alguns pais entenderem que estavam educando os seus filhos ao conterem e até "brigarem" com eles, esses achados demonstram o quanto a forma dos pais interagirem com os bebês variava consideravelmente. Em alguns momentos, os pais podiam ser mais afetivos, quando cuidavam e brincavam com o filho, e em outros podiam ser mais agressivos, quando tentavam colocar limites. Isto corrobora com Winnicott (1958/2005), ao destacar que por meio dos cuidados maternos, os aspectos paternos começam a ser sentidos e diferenciados pelo bebê e o pai vai trazendo qualidades de firmeza, rigor, ordem, força, limite e introdução do "não" (Fulgencio, 2007).

Apesar de os pais, de modo geral, interagirem de diversas maneiras com os seus filhos no tempo que dispunham para estar com a família, este tempo foi avaliado por eles como bastante limitado, sobretudo devido ao trabalho. Tal resultado vai ao encontro de outros estudos (Gabriel \& Dias, 2011; Sutter \& BucherMaluschke, 2008), os quais mostraram que a elevada carga horária de trabalho seria o principal fator que dificulta uma maior participação do pai na vida do bebê. Esta limitação já havia sido relatada por estes pais, aos três meses de vida do bebê (Piccinini et al., 2012), quando também avaliaram como pouco o tempo que dedicavam ao filho.

Vale ainda destacar que, a despeito do emprego, a maioria dos pais relatou reservar ou disponibilizar parte do seu dia para estar junto do bebê. Tal achado pode apontar o desejo e o esforço dos pais por um maior envolvimento com seus filhos e a possibilidade de vivenciarem os prazeres e ganhos oriundos do convívio próximo com o bebê (Seward, Yeatts, \& Zottarelli, 2002). Ainda nesse sentido, alguns pais caracterizaram como gratificante o tempo que passavam com o filho e disseram sentir saudades do bebê quando estavam afastados dele, o que ajuda a sustentar essa ideia. Contudo, chama a atenção que poucos referiram sentir saudades do bebê, o que sugere que apesar do tempo restrito que dispunham para o bebê, este podia estar sendo visto como suficiente.

Por outro lado, estes relatos também podem ser reflexo da crescente cobrança social e da esposa de que o pai participe de maneira mais próxima da criação dos filhos, não sendo tão valorizada e aceita a figura do pai apenas como provedor do sustento econômico familiar (Seward et al., 2012), mesmo porque muitas das mães do presente estudo também trabalhavam e precisavam compartilhar os cuidados do bebê. Destaca-se ainda que alguns pais, diante das demandas e das necessidades do bebê, que por vezes exigia que levantassem à noite devido ao choro, nem sempre demonstraram a disponibilidade física e emocional necessária para se dedicarem e se devotarem à tarefa de cuidar de bebês (Winnicott, 1987/2006). Ao participarem dos cuidados do bebê, por obrigação e dever, podem não contribuir 
para a interação com o filho, que acaba percebendo a falta de disponibilidade emocional do pai.

Com relação às responsabilidades e preocupações dos pais aos 12 meses do bebê, destaca-se a decisão pelo cuidado não parental e as discussões sobre o modo de cuidar e educar escolhido pelo pai e pela mãe. Dentre as opções, destacam-se a creche, o cuidado por parentes ou pela babá. Os pais consideraram, na maior parte das vezes, a incerteza de como o filho seria tratado por pessoas diferentes dele ou da mãe. Além disso, os pais conversavam com a mãe sobre o assunto, assim como sobre o modo como eles próprios gostariam de educar o bebê, especialmente quando o bebê não estaria agindo de forma adequada. Diferente dos três meses do bebê (Piccinini et al., 2012), neste momento a decisão pelo cuidado alternativo se fez mais presente, muitas vezes associada à necessidade e/ou ao desejo da mãe em voltar a trabalhar, além de querer que a criança convivesse com outras crianças.

Ainda no que concerne às responsabilidades, os pais relataram que a mãe era a principal responsável pelos cuidados do bebê, mesmo que eles também participassem da rotina quando estavam presentes e compartilhassem preocupações com a saúde e desenvolvimento deste. Como citado anteriormente, além da disponibilidade de tempo, alguns pais relataram não se sentirem tão hábeis e competentes quanto às mães no momento de exercer as atividades com o bebê. Talvez a falta de oportunidades para o pai conhecer o seu filho e, a partir disso, aprender a reconhecer e entender as suas expressões e sinais de desconforto, contribuía para que se tornassem mais "auxiliares" das mães do que "protagonistas" nesse momento. Esses resultados também foram encontrados aos três meses do bebê (Piccinini et al., 2012), sugerindo que, para os pais, as novas habilidades do bebê aos 12 meses, ainda não facilitavam muito o envolvimento e manejo do pai.

Cabe ainda refletir sobre aqueles pais que não fizeram relatos que pudessem ser classificados nas categorias de análise. Por exemplo, com relação à interação, alguns pais (20\%) não mencionaram situações em que interagiam com os bebês. Isto pode estar relacionado com o fato de o pai ter pouco contato com o filho ou de não conseguir reconhecer ou ter prazer em interagir com o filho, ou mesmo dificuldade de se expressar em uma entrevista, mas também por falta de paciência, como foi mencionado. Sem dúvida, a pouca disponibilidade de tempo pode limitar a interação com o filho, especialmente a sua qualidade. Além disto, a responsabilização da mãe pelos cuidados do bebê também pode contribuir a ponto de ter pouco contato com o filho. Para além disto, a interação do pai com o bebê com um ano de vida pode estar também relacionada ao envolvimento do pai desde a gestação, e que vai se ampliando ao longo do tempo (Tamis-LeMonda, Kahana-Kalman, \& Yoshikawa, 2009). Soma-se a isto o fato de os pais muitas vezes terem uma percepção de menor eficácia parental quando comparando à mãe (Ferreira et al., 2014). Mesmo considerando todas estas explicações, é preocupante perceber que um número expressivo de pais não referiram interações com o bebê, especialmente considerando que se tratava do primeiro filho do casal. Isto sugere que o envolvimento paterno pode variar muito, oscilando entre pais que interagem bastante com o bebê e pais que pouco ou nada interagem.

Um número também expressivo de pais $(25 \%)$ não fez referência sobre a quantidade de tempo disponibilizada ao bebê, sugerindo que eles passavam pouco ou nenhum tempo com o filho. A ausência destes relatos pode refletir um sentimento de pesar destes pais por perceberem que passavam pouco tempo com o bebê. Estes pais tenderam a colocar o trabalho como uma explicação para essa indisponibilidade, justificando seu envolvimento indireto, já que a mãe permanece mais tempo perto do bebê. De qualquer modo, nesta categoria de análise também apareceu uma variação muito grande, com os pais que ficavam muito tempo com o filho e os que pouco ou nenhum tempo dispunham para ele.

Mesmo existindo em nossa sociedade a tendência a uma atualização do papel paterno, que passou a ser mais participativo (Vieira et. al, 2014), muitos pais do presente estudo ainda pareceram apoiar seu envolvimento em aspectos típicos e esperados de um pai mais tradicional - embora não menos importantes -, como ser provedor para retratar sua paternidade como positiva. Neste sentido, chamou atenção a inexistência de relatos em que os pais se mostrassem preocupados com a sua relação com o bebê ou com o desenvolvimento emocional do filho. Além disto, considerando as novas perspectivas de papel paterno, esperava-se uma maior reflexão acerca da importância da divisão de tarefas com a mãe, sobretudo o quanto isso pode acabar acarretando um maior distanciamento do pai do cotidiano do bebê, privando-o de estar perto dele para acompanhar e fazer parte das descobertas e do desenvolvimento do bebê. Ainda, ao não se envolver com os cuidados do bebê, o pai pode acabar reduzindo as oportunidades de estabelecer uma relação íntima com o filho, de conhecê-lo para poder atender as suas necessidades e, ao fazer isso, sentir-se competente como pai e cuidador.

Por fim, é importante destacar que os resultados do presente estudo estão associados a um contexto específico, que envolvia o primeiro filho, sendo que 
o casal residia junto com o bebê em um grande centro urbano. Nesse sentido, sugere-se a realização de outros estudos que investiguem não só o envolvimento paterno em outras fases do desenvolvimento infantil, mas também em diferentes contextos, configurações familiares, bem como os aspectos subjetivos envolvidos na paternidade. De qualquer modo, o presente estudo traz contribuições para se entender alguns aspectos da paternidade, particularmente aos 12 meses de vida do filho, idade em que o bebê passa a ser mais responsivo, contribuindo para uma maior participação do pai.

\section{Considerações Finais}

Os resultados do presente estudo revelaram as diversas formas do pai se envolver com o seu bebê aos 12 meses. O bebê neste momento ainda é extremamente dependente do cuidado e da atenção dos adultos, e os pais, de modo geral, respondiam às necessidades e demandas do filho. Por sua vez, ainda que de modo incipiente, os bebês também já apresentavam novas habilidades e buscavam atenção para suas demandas, ainda que nem sempre aceitas e atendidas pelos pais. As manifestações do bebê quanto às suas vontades e preferências trouxeram para os pais novas demandas de interação, que por vezes eram atendidas para satisfazê-lo, mas em outras não o eram, usando inclusive contenção física. Muitos pais mostraram-se competentes para lidar com as novas habilidades do bebê, mesmo que, em alguns momentos, eles pareciam sentir dificuldades em lidar ou ainda preferir que a mãe fizesse as atividades menos agradáveis, como levantar a noite, trocar fraldas e atender ao choro. Além disso, a necessidade da família em buscar um cuidado não parental para o bebê trouxe um maior sentimento de responsabilidade e de preocupação nos pais, que percebiam o filho como ainda muito pequeno para ser deixado com outras pessoas, embora a necessidade familiar deixasse os pais sem muitas opções.

É importante ainda destacar que, para fins de análise e exposição, as três dimensões do envolvimento paterno foram apresentadas separadamente. Contudo, elas não são independentes uma da outra e seria mais adequado apresentá-las de um modo mais dinâmico, já que se influenciavam mutuamente e cada uma potencializa as outras, afetando a qualidade do envolvimento paterno na vida do filho. Por exemplo, a maior ou menor disponibilidade psíquica e temporal do pai influencia diretamente a forma como este interage com o bebê, bem como os sentimentos de responsabilidade e preocupação que ele vivencia.

Os resultados do presente estudo sugerem que os profissionais de saúde precisam atentar para as dúvidas e angústias dos pais, facilitando o seu envolvimento com o bebê e com os cuidados que a própria mãe vai assumindo. Ao se acolher as preocupações não só maternas, mas também paternas, se estará contribuindo para promover a participação do pai na vida do bebê. Além disso, ao se criar um espaço de escuta às dúvidas maternas e paternas sobre a parentalidade e sobre o desenvolvimento do bebê, se estará sensibilizando a ambos, mas particularmente o pai, a sentir-se cada vez mais competente e emocionalmente disponível para as atividades de cuidar e educar o bebê, contribuindo para a sua conscientização sobre a importância da sua presença na vida do filho. Isto contribuirá para que os pais possam despertar sua sensibilidade e descobrir a satisfação de cuidar do filho, estabelecendo com ele um relacionamento íntimo que terá impacto não só no desenvolvimento emocional do filho, mas do próprio pai.

\section{Referências}

Altafim, E. R. P., Schiavo, R. A., \& Rodrigues, O. M. P. R. (2008). Práticas parentais de mães adolescentes: um estudo exploratório. Temas sobre Desenvolvimento, 16(93), 104-110.

Brown, G. L., Mangelsdorf, S. C., \& Neff, C. (2012). Father involvement, paternal sensitivity, and father-child attachment security in the first 3 years. Journal of Family Psychology, 26(3), 421-430. http://dx.doi.org/10.1037/a0027836

Carvalho, A. M. A., Pedrosa, M. I., \& Rossetti-Ferreira, M. C. (2012). Aprendendo com a criança de zero a seis anos. São Paulo: Cortez.

Castoldi, L., Gonçalves, T. R., \& Lopes, R. C. S. (2014). Envolvimento paterno da gestação ao primeiro ano de vida do bebê. Psicologia em Estudo (Maringá), 19(2), 247-259. http://dx.doi.org/10.1590/1413-737222105008

Falceto, O. G., Fernandes, C. L., Baratojo, C., \& Giugliani, E. R. J. (2008). Fatores associados ao envolvimento do pai nos cuidados do lactente. Revista de Saúde Pública, 42(6), 1034-1040. http://dx.doi.org/10.1590/S003489102008000600009

Ferreira, B., Monteiro, L., Fernandes, C., Cardoso, J., Veríssimo, M., \& Santos, A. J. (2014). Percepção de Competência Parental: Exploração de domínio geral de competência e domínios específicos de autoeficácia, numa amostra de pais e mães portuguesas. Análise Psicológica, 32(2), 145-156. http://dx.doi.org/10.14417/ap.854

Frascarolo, F. (2004). Paternal involvement in child caregiving and infant sociability. Infant Mental Health Journal, 25(6), 509-521. http://dx.doi.org/10.1002/imhj.20023 
Fuertes, M., Faria, A., Breeghly, M., \& Santos, P. L. (2015). The effects of parental sensitivity and involvement in caregiving on mother-infant and father-infant attachment in a portuguese sample. Journal of Family Psychology, 5, no pagination specified.

Fulgencio, C. D. R. (2007). A presença do pai no processo de amadurecimento: um estudo sobre D. W. Winnicott. Dissertação de mestrado não publicada. Pontifícia Universidade Católica de São Paulo, São Paulo, Brasil.

Gabriel, M. R. \& Dias, A. C. G. (2011). Percepções sobre a paternidade: descrevendo a si mesmo e o próprio pai como pai. Estudos de Psicologia, 16(3), 253-261. http://dx.doi.org/10.1590/S1413-294X2011000300007

Kong, S. Y. C. L., Ling, C. C. Y., Leung, C. L. K., \& Li, J. C. M. (2013). Fathering self-efficacy, marital satisfaction and father involvement in Hong Kong. Journal of Child and Family Studies, 22, 1051-1060. http://dx.doi.org/10.1007/ s10826-012-9666-1

Lamb, M. E., Pleck, J. H., Charnov, E. L., \& Levine, J. A. (1985). Paternal behavior in humans. American Zoologist, 25(3), 883-894. http://dx.doi.org/10.1093/icb/25.3.883

Laville, C. \& Dione, J. (1999). A construção do saber: manual de metodologia da pesquisa em ciências humanas. Porto Alegre: Artes Médicas.

Lindsey, E. W., Cremeens, P. R., \& Caldera, Y. M. (2010). Gender differences in mother-toddler and father-toddler verbal initiations and responses during a caregiving and play context. Sex Roles, 63(5-6), 399-411. http://dx.doi.org/10.1007/ s11199-010-9803-5

McHale, J. P., Kazali, C., Rotman, T., Talbot, J., Carleton, M., \& Lieberson, R. (2004). The transition to coparenthood: parents' prebirth expectations and early coparental adjustment at 3 months postpartum. Development and Psychopathology, 16(3), 711-733. http://dx.doi.org/10.1017/S0954579404004742

Nordahl, K. B., Jason, H., Manger, T., \& Zachrisson, H. D. (2014). Family concordance and gender differences in parent-child structured interaction at 12 months. Journal of Family Psychology, 28(2), 253-259. http://dx.doi.org/10.1037/a0035977

Piccinini, C. A., Silva, M. R., Gonçalves, T. R., Lopes, R. C. S. L., \& Tudge, J. (2004). O envolvimento paterno durante a gestação. Psicologia: Reflexão e Crítica, 17(3), 303-314. http://dx.doi.org/10.1590/S0102-79722004000300003

Piccinini, C. A., Silva, M. R., Gonçalves, T. R., Lopes, R. C. S. L., \& Tudge, J. (2012). Envolvimento paterno aos três meses de vida do bebê. Psicologia: Teoria e Pesquisa, 28(3), 303-314. http://dx.doi.org/10.1590/S0102-37722012000300006

Piccinini, C. A., Tudge, J., Lopes, R. C. S., \& Sperb, T. (1998). Estudo longitudinal de Porto Alegre: da gestação à escola. Instituto de Psicologia - UFRGS, Porto Alegre. Projeto de pesquisa não publicado.

Premberg, A., Hellström, A. L., \& Berg, M. (2008). Experiences of first year as father. Scandinavian Journal of Caring Sciences, 22, 56-63. http://dx.doi.org/10.1111/j.1471-6712.2007.00584.x

Saleh, M. F. \& Hilton, J. M. (2011). A comparison of the paternal involvement of low-income fathers in four development stages: adolescence, young adult, adult, and midlife. The Familý Journal, 19(1), 47-55. http://dx.doi. org/10.1177/1066480710387496

Sary, M. P. \& Turnip, S. S. (2015). Attitude difference between fathers and mothers toward father involvement in child rearing activities among couples with $0-12$ months old babies. Community based study in a primary health care setting. Procedia - Social and Behavioral Sciences, 190(21), 92-96. http://dx.doi.org/10.1016/j.sbspro.2015.04.921

Seward, R. R., Yeatts, D. E., \& Zottarelli, L. K. (2002). Parental leave and father involvement in child care: Sweden and the United States. Journal of Comparative Family Studies, 33(3), 387-399.

Sutter, C. \& Bucher-Maluschke, J. S. N. F. (2008). Pais que cuidam dos filhos: a vivência masculina da paternidade participativa. Psico, 39(1), 74-82.

Tamis-LeMonda, C. S., Kahana-Kalman, R., \& Yoshikawa, H. (2009). Father involvement in immigrant and ethnically diverse families from the prenatal period to the second year: prediction and mediating mechanisms. Sex Role, 60, 496-509. http://dx.doi.org/10.1007/s11199-009-9593-9

Vieira, M. L., Bossardi, C. N., Gomes, L. B., Bolze, S. D. A., Crepaldi, M. A., \& Piccinini, C. A. (2014). Paternidade no Brasil: revisão sistemática de artigos empíricos. Arquivos Brasileiros de Psicologia, 66, 36-52.

Winnicott, D. W. (1982). A criança e o seu mundo. Rio de Janeiro: LTC Editora. (Original published in 1957)

Winnicott, D. W. (2005). A familia e o desenvolvimento individual. São Paulo: Martins Fontes. (Original published in 1958). Winnicott, D. W. (2006). Os bebês e suas mães. São Paulo: Martins Fontes. (Original published in 1987).

\section{Autores:}

Rodrigo Gabbi Polli - Doutorando, Universidade Federal do Rio Grande do Sul.

Marília Reginato Gabriel - Doutoranda, Universidade Federal do Rio Grande do Sul.

Cesar Augusto Piccinini - Doutor, Universidade Federal do Rio Grande do Sul.

Rita de Cassia Sobreira Lopes - Doutora, Universidade Federal do Rio Grande do Sul.

\section{Endereço para correspondência:}

Rodrigo Gabbi Polli

Instituto de Psicologia, UFRGS - Campus Universitário

Rua Ramiro Barcelos, 2600 sala 108/111 - Santa Cecília

90035-003 Porto Alegre, RS, Brasil

<ropsiufsm@gmail.com>

Recebido em: 27.02.2016

Aceito em: 24.05.2016 